\title{
Sensitivity of Summer Monsoon Precipitation over East Asia to Convective Parameterization Schemes in RegCM3
}

\author{
G. P. Singh*, Jai-Ho Oh, Jin-Young Kim and Ok-Yeon Kim \\ Department of Environment and Atmospheric Sciences \\ Pukyong National University, Busan, South Korea
}

\begin{abstract}
This study investigates some of the important characteristics of summer monsoon circulation and precipitation over East Asia in general and Korea in particular using the recent version of NCAR Regional Climate Model (RegCM3). RegCM3 has been integrated at $27 \mathrm{~km}$ horizontal resolution over the East Asian domain for the period from 1998 to 2002 (5 years). The important characteristics of temperature and wind at upper and lower levels and precipitation simulated by the RegCM3 over South Korea are examined in detail using different convective parameterization schemes namely, mass flux schemes, a simplified Kuo-type scheme and Emanuel (EMU) scheme. The monsoon circulation features (wind and temperature) simulated by RegCM3 are compared with those of the NCEP/NCAR reanalysis (Kalnay et al. 1996) and simulated summer precipitation in JJA (average of June to August) over Korea (KMR) is validated against the observation from Korea Meteorological Administration (KMA). Validation of simulated precipitation with KMA shows that the use of the Arakawa and Schubert (AS) and EMU convection schemes are more close to the KMA. The statistical analysis (area average precipitation, standard deviation and correlation analysis) also indicates that the use of EMU and AS schemes perform better over East Asia particularly over Korea.
\end{abstract}

\section{Introduction}

The East Asian summer monsoon system is dominant mainly over China, Japan and Korea. The most significant weather phenomenon of summer monsoon over East Asia is the quasi-stationary front extending from South China Sea to southern Japan. This front is known as Baiu in Japan, Changma in Korea and Meiyu in China. About 50-60\% of the annual rainfall over this region occurs during northern summer. In this study, we have focused precipitation mainly over Korea region using RegCM3 model.

Most of the studies in the past (IPCC 1996) have shown that by using higher spatial resolution to represent local effects of surface topography, vegetation, and land-sea contrast regional climate models can produce reasonable simulations of precipitation which are highly affected by regional features of the lower boundary conditions. At the same time, numerous studies have also suggested that the regional climate simulations could be very sensitive to the physical parameterizations schemes used. For example, Giorgi (1990) conducted a detailed analysis of summer time

Corresponding author: Jai-Ho Oh, Integrated Climate System Modeling Group, Department of Environmental Atmospheric Sciences, Pukyong National University, 599-1 Daeyeon3-dong, Nam-gu, Busan 608-737, South Korea. E-mail: jhoh@pknu.ac.kr. * Permanent affiliation: Department of Geophysics, Banaras Hindu University, Varanasi, India.

(C)2006, the Meteorological Society of Japan. regional simulation over the western United States focusing on problem associated with unrealistically intense precipitation simulated over isolated grid points. These are sensitive to the physical parameterizations used in the model and reduce their skill in simulating precipitation over mountainous areas. Furthermore, depending on the relative strength of local forcings, such as surface topography and the influence of large scale circulations on regional simulations, the skill of regional models can also be significantly affected by errors associated with the large scale conditions used to provide lateral boundary conditions for the regional models. This study focuses on the effects of different convective parameterization schemes in the regional climate simulation. We have focused mainly precipitation fields simulated with RegCM3. Section 2 describes the details of model and simulated results are discussed in Section 3. Conclusions are given in Section 4.

\section{Model descriptions}

The RegCM3 model has been developed over last decades at NCAR. RegCM3 has mostly been tested over the United States, Europe and East Asia (particularly over China). RegCM3 is not tested in detail over Korea yet. The model used in this study is the recent version of NCAR RegCM originally developed by Giorgi et al. (1993 a,b) and then augmented as discussed by Pal et al. (2000). The model dynamical core is essentially the same as that of the hydrostatic version of the meso-scale model MM5 Grell et al. (1994). The RegCM3 includes the large scale precipitation scheme of Pal et al. (2000), the radiative transfer scheme of the global model CCM3 (Community Climate Model 3) and the ocean-atmosphere flux scheme (Zeng et al. 1998). In this study, we have used three convective parameterizations schemes. The first is a simplified Kuo-type parameterization (Grell et al. 1994), which has been widely used for many years. In this scheme convection is triggered when vertical profile is convectively unstable and the vertically integrated moisture convergence exceeds a certain threshold. Once, convection is initiated, a fraction of the moisture convergence goes into precipitation while the remaining fraction moistens the atmospheric column following a prescribed vertical profile. The vertical moistening depends on the local relative humidity i.e., more moisture is allocated at the drier points. The second scheme we have used is also extensively used within both the MM5 and RegCM modeling frame work. This is a mass flux scheme that includes the moistening and heating effects of penetrative updrafts and corresponding downdrafts. The second scheme has two closer assumptions, the so called Arakawa-Schubert (hereafter referred to as AS) and the Fritsch-Chappell (hereafter referred to as a FC) type closures. Both are used in this study. The third scheme is by Emanuel (1991) (hereafter referred to as EMU). Under this scheme, fundamental entities are sub-cloud scale draft rather than cloud themselves. 

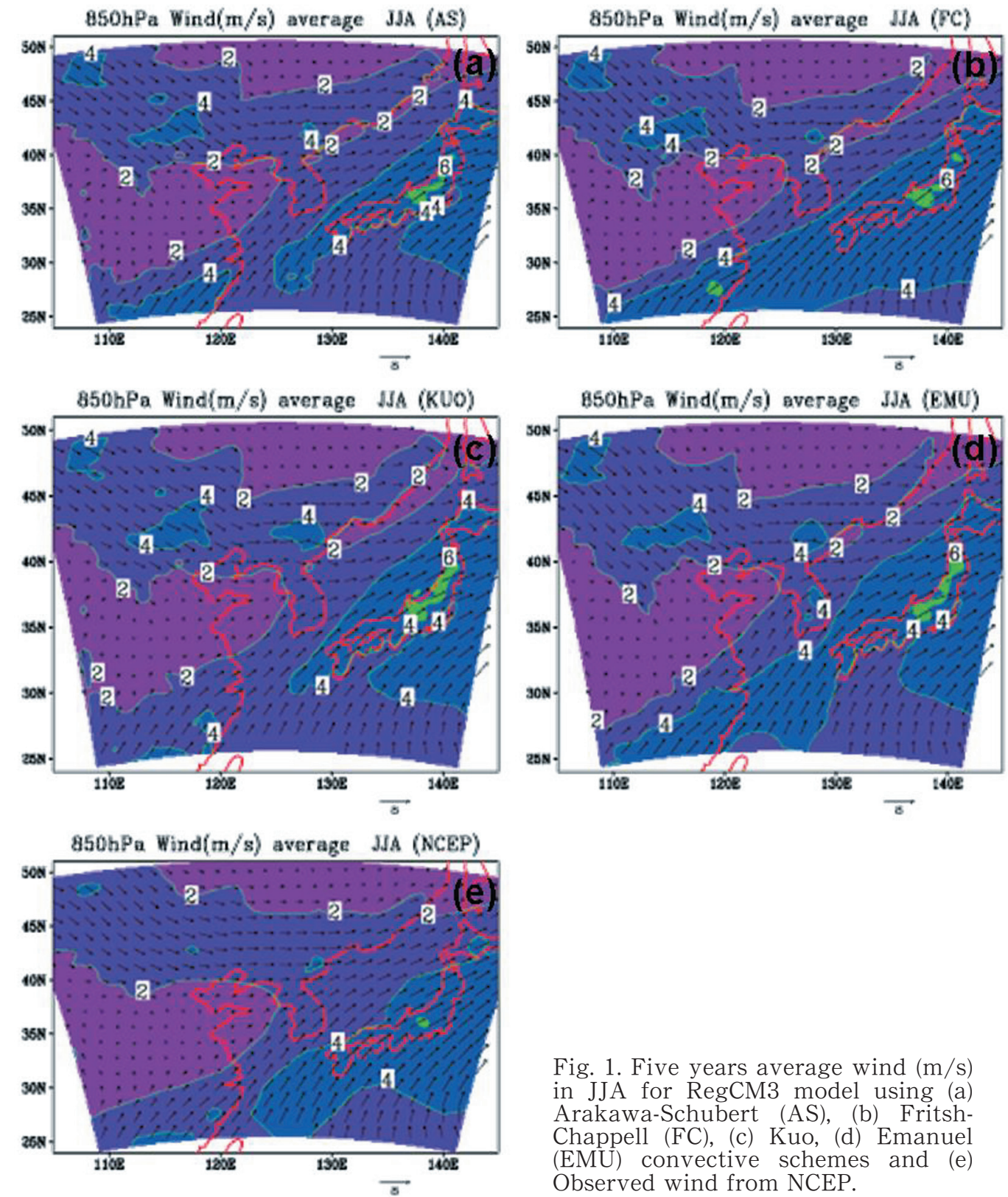

Fig. 1. Five years average wind $(\mathrm{m} / \mathrm{s})$ in JJA for RegCM3 model using (a) Arakawa-Schubert (AS), (b) FritshChappell (FC), (c) Kuo, (d) Emanuel (EMU) convective schemes and (e) Observed wind from NCEP.

The period of RegCM3 simulations are from 1998 to 2002 for the purpose of present study. The computation domain covers the area approximately $24^{\circ} \mathrm{N}-48^{\circ} \mathrm{N}$ and $109^{\circ} \mathrm{E}-148^{\circ} \mathrm{E}$ with a grid point spacing at $27 \mathrm{~km}$. The central point of the domain is at $38^{\circ} \mathrm{N}$ and $125^{\circ} \mathrm{E}$. There are 105 points along latitude direction and 125 points along longitude direction. Thus the model domain covers the large area to allow for full development of internal model meso-scale circulations and include relevant regional forcings. For validation of simulated precipitation, daily rainfall data for 59 stations spread over South Korea, are used during summer monsoon (June to August) from 1998 to 2002 from Korea Meteorological Administrative (KMA). The observed (KMA) precipitation over 59 stations is interpolated using Barnes (1964) objective analysis to improve meteorological analyses on the mesoscale grid by incorporating information from observations.

\section{Simulation of mean monsoon features}

The seasonal wind fields simulated by RegCM3 at lower level $(850 \mathrm{hPa})$ have the maximum strength of westerly by $4 \mathrm{~m} / \mathrm{s}$ and tropical southerly by $6 \mathrm{~m} / \mathrm{s}$ mainly over Japan (Fig. 1). Similarly, maximum strength of the simulated westerly at upper level $(200 \mathrm{hPa})$ is $25 \mathrm{~m} / \mathrm{s}$. This result shows that mean monsoon wind fields at lower and upper levels are close to the NCEP/NCAR reanalysis. While spatial distribution of seasonal temperature fields $(850 \mathrm{hPa}$ and $500 \mathrm{hPa})$ (not shown) shows that RegCM3 seems to be characterized by cold biases of few degrees particularly over Korea and Japan peninsula. Giorgi et al. (2004) shows that cold bias in RegCM3 simulation may be caused by the physical parameterizations such as non local boundary layer, convection and land surface scheme. A comparison of simulated temperature and wind patterns 



Fig. 2. Five years average precipitation $(\mathrm{mm} /$ day) in JJA for RegCM3 model using (a) Arakawa-Schubert (AS), (b) Fritsh-Chappell (FC), (c) Kuo, (d) Emanuel (EMU) convective schemes and (e) Observed precipitation from KMA.

with NCEP/NCAR reanalysis fields indicate that the EMU scheme exhibits a better simulation compared to other convective schemes used in RegCM3 over East Asia particularly over Korean peninsula.

Figure 2 shows the 5 years average precipitation field only for the interior of the domain (only over South Korean peninsula) in order to more clearly illustrate the fine scale topographical induced details. Figure $2(a-d)$ shows the precipitation rate $(\mathrm{mm} / \mathrm{day})$ simulated with RegCM3 during summer monsoon season (average of June, July and August) using AS, FC, a Kuo-type and EMU convection schemes in RegCM3. Figure 2(e) shows the observed precipitation rate $(\mathrm{mm} /$ day) from KMA. The spatial gradient near North and South Korea is due to orography and consistent with summer climatology over this region (e.g., Kim et al. 2002) RegCM3 simulation with AS scheme shows the maximum precipitation of $8 \mathrm{~mm} /$ day over major parts of Korea and $10 \mathrm{~mm} /$ day over east coast of Korea, while FC scheme shows the maximum precipitation of $10 \mathrm{~mm} /$ day over small area of southwest coast. When using Kuo-type scheme, RegCM3 shows the maximum precipitation of $12 \mathrm{~mm} /$ day over central southern coast and smaller over east coast. For EMU scheme, the model shows the maximum precipitation of $12 \mathrm{~mm} /$ day over major parts of Korean peninsula and $14 \mathrm{~mm} /$ day over central northeast Korean peninsula. The observed precipitation from KMA shows three zones of maximum precipitation. These are over southern coast (12 mm/day), central east coast $(14 \mathrm{~mm} /$ day) and central north $(14 \mathrm{~mm} /$ day $)$. Spatial distribution of precipitation in JJA also shows that EMU and AS convective schemes are performing slightly better to other convective schemes when compared to KMA.

Figure 3 compares the simulated mean precipitation in JJA over Korea for the years 1998 to 2002 along with the composite of the five years, with corresponding observed values of KMA dataset. As seen from Fig. 3, a good agreement is found between the precipitation simulated with EMU and AS schemes and the KMA 




Fig. 3. Comparison of JJA mean precipitation (mm/day) over Korea simulated by RegCM3 in As, EMU, KUO and FC convection schemes with KMA observed precipitation.

observed precipitation over Korean peninsula. An analysis of inter-annual standard deviation of precipitation in the KMA and in the RegCM3 also shows good agreement with EMU and AS schemes. Similarly, Correlation Coefficients (CCs) between RegCM3 simulated daily precipitation and observed (KMA) daily precipitation from June to August show the CCs of 0.62 for EMU, 0.61 for AS, 0.55 for Kuo and 0.51 for FC convective schemes. Although, all the CCs are significant at $0.1 \%$ levels but EMU and AS have high values of correlations.

Over all, a comparison of observed and RegCM3 simulated precipitation shows that the model captured some of the maximum values of high precipitation area reasonably well. Validation against KMA data sets also show that the precipitation simulated with the EMU and AS convection schemes are closer compared with the other convective schemes. The RegCM3 simulation locates the area of maximum precipitation approximately over south and east coast and the minimum over northwest coast of South Korea, which are in good agreement with observation (KMA).

\section{Conclusions}

The RegCM3 modeling system has been extensively used for various regional climate studies. It has not been widely tested over East Asia particularly over South Korea mainly for monsoon studies. In this paper, RegCM3 has been integrated over East Asia regions using different cumulus parameterization schemes. Results indicate that the RegCM3 successfully simulates some of important characteristics of the East Asian monsoon circulations, such as tropical southerlies and mid latitude westerlies at lower level and westerlies at $200 \mathrm{hPa}$. Also, the seasonal mean summer monsoon precipitation simulated by RegCM3 is closer to the corresponding observed value of KMA when the EMU and AS convective schemes are used. Various statistical measures such as mean, standard deviation and correlation analysis show that EMU and AS schemes perform better particularly over Korea. In general, Emanuel scheme performed better than AS, FC and Kuo schemes in simulating both the monsoon circulations and precipitation. The possible reason for these schemes performing better is due to their ability to simulate humidity evolution better (Emanuel and Rothman 1999). Though only 5-years of inter-annual variability is examined here, the simulation of variability over South Korea is reasonably good. In sum, our preliminary results indicate that RegCM3 can be effectively used to study the monsoon processes over South Korea regions. In the future, we plan to perform long period simulation and different sensitivity experiments with RegCM3 to get more statistical significant results.

\section{Acknowledgments}

This work was funded by the Korea Meteorological Administration Research and Development Program under Grant CATER_20061001. The authors would like to acknowledge the support from KISTI (Korea Institute of Science and Technology Information) under the 'Sixth Strategic Supercomputing Support Program' with Dr. Lee Sang Min and Dr. Cho Kum Won as the technical supporter. The use of the computing system of the Supercomputing Center is also greatly appreciated. First author wish to acknowledge the KOFST for supporting the visit.

\section{References}

Barnes, S. L., 1964: A technique for maximizing details in numerical weather map analysis. J. Appl. Meteor., 3, 396409.

Emanuel, K., 1991: A scheme for representing cumulus convection in large scale models. J. Atmos. Sci., 21, 2313-2335.

Emanuel, K., and M. Z. Rothman, 1999: Development and evaluation of a convection scheme for use in climate models, J. Atmos. Sci., 56, 1766-1782.

Giorgi, F., 1990: On the simulation of regional climate using a limited area model nested in a general circulation model. J. Climate, 3, 941-963.

Giorgi, F., M. R. Marinucci and G. T. Bates, 1993a: Development of a second generation regional climate model (RegCM2). Part-I. Boundary layer and radiative transfer processes. Mon. Wea. Rev., 121, 2794-2813.

Giorgi, F., M. R. Marinucci, G. T. Bates and G. DeCanio, 1993b: Development of a second generation regional climate model (RegCM2). Part-II. Convective processes and assimilation of lateral boundary conditions. Mon. Wea. Rev. 121, 2814-2832.

Giorgi, F., X. Bi and J. S. Pal, 2004: Mean, interannual variability and trends in a regional climate change experiment over Europe. 1. Present-day climate (1961-1990). Clim. Dyn., 22, 733-756.

Grell, G. A., J. Dudhia and D. R. Stauffer, 1994: A description of the fifth generation Penn State/NCAR mesoscale model (MM5). NCAR Technical Notes, NCAR/TN-398+STR, 12.

Intergovernmental Panel on Climate Change (IPCC), 1996: Climate change in The Science of Climate Change, edited by J. T. Houghton, L. G. Meira, B. A. Callander, N. Harris, A. Kattenberg and K. Maskell, Cambridge Univ, $572 \mathrm{pp}$.

Kalnay, E., M. Kanamitsu, R. Kistler, W. Collins, D. Deaven, L. Gardin, M. Iredell, S. Saha, G. White, J. Wollen, Y. Zhu, M. Chelliah, W. Ebisuzaki, W. Higgins, J. Janowiak, K. C. Mo, C. Ropelewski, J. Wang, A. Leetmass, R. Reynolds, R. Jenne and D. Joseph, 1996: The NCEP/NCAR 40-year reanalysis project. Bull. Amer. Meteor. Soc., 77, 437-471.

Kim, B. J., R. H. Kripalani, J. H. Oh and S. E. Moon, 2002: Summer monsoon rainfall patterns over South Korea and associated circulation features. Theor. Appl. Climatol., 72, 65-74.

Pal, J., E. E. Small and E. A. B. Eltahir, 2000: Simulation of regional scale water and energy budget: representation of subgrid cloud and precipitation processes within RegCM. J. Geophys. Res., 105, 29579-29594.

Zeng, X., M. Zao and R. E. Dickinson, 1998: Intercomparsion of bulk aerodynamic algorithm for the computation of sea surface fluxes using Toga care and Tao data. J. Climate, 11, 2628-2644.

Manuscript received 24 October 2005, accepted 6 February 2006 SOLA: http://www.jstage.jst.go.jp/browse/sola/ 